Acta Theriologica 38 (2): 139 - 150, 1993.

PL ISSN 0001 - 7051

\title{
Growth, size, and fat reserves of the raccoon dog in Finland
}

\author{
Kaarina KAUHALA
}

Kauhala K. 1993. Growth, size, and fat reserves of the raccoon dog in Finland. Acta theriol. 38: $139-150$.

The growth, size, and fat reserves of the raccoon dog Nyctereutes procyonoides (Gray, 1834) were studied in Finland in period 1986 - 1990. There was no sexual dimorphism in mean body size. Juveniles reached the mean adult body length at the age of $5-7$ months. The weather in spring seemed to cause both annual and regional variation in the weight and fat reserves of juveniles in late autumn. Some of these differences could be seen as late as the following March, the breeding season of raccoon dogs. The adults had the least fat reserves in May and the most in October November. The abundance of food, especially that of voles in early spring, seemed to affect the fat reserves of adult females in March.

Finnish Game and Fisheries Research Institute, Game Division, P. O. Box 202, FIN-00151 Helsinki, Finland

Key words: Nyctereutes procyonoides, growth, size, fat reserves, Finland

\section{Introduction}

The Far East is the original distribution area of the raccoon dog Nyctereutes procyonoides (Gray, 1834), but it was introduced to the northwestern parts of the former Soviet Union between 1935 and 1953 (Lavrov 1971). From there the raccoon dog dispersed, colonizing southern and central Finland by the mid-1970s. The population increased very rapidly in southern Finland, but the growth rate further north was slow. The population density is now higher than that of the red fox Vulpes vulpes in southern Finland but is still low further north (game inquiries and kill statistics of Finnish Game and Fisheries Research Institute, Helle and Kauhala 1991a).

The raccoon dog is a small canid which sleeps during winter in areas where the winter is hard and gathers large fat reserves before winter sleep (Novikov 1962, Ognev 1962, Stroganov 1969, Judin 1977). Although the raccoon dog is omnivorous (Bannikov 1964, Nasimovič and Isakov 1985), small mammals (voles, mice, and shrews) and berries constitute a large part of its diet in Finland (Kauhala et al., in press), and also seem to affect the annual variation in the population density (Helle and Kauhala 1991a, Kauhala 1992) as well as productivity (Helle and Kauhala 1991b). 
The data presented herein illustrate the regional, seasonal and annual variation in body length, weight, and fat reserves of raccoon dogs in Finland. Also, I try to establish whether climate or food availability can affect the growth or fat reserves of the raccoon dog. The effects of growth rate, weight, and fat reserves on the population dynamics of the raccoon dog will be discussed elsewhere.

\section{Material and methods}

Carcasses of raccoon dogs $(n=1515)$ were collected from hunters between 1986 and 1990. Most carcasses came from the provinces of Häme and Kymi (Fig. 1), but I also received some from the province of North Karelia and the provinces of Turku-Pori and Uusimaa. Most animals were killed between the beginning of August and the end of May. Fifty three raccoon dogs were also caught alive in traps set near Evo Game Research Station in Häme $\left(61^{\circ} 14^{\prime} \mathrm{N}, 25^{\circ} 10^{\prime} \mathrm{E}\right)$ and ear-tagged. These raccoon dogs were weighed each time they were handled.

Altogether, 1515 carcasses were weighed to within $20 \mathrm{~g}$, and 1473 carcasses were measured from the tip of the nose to the anus to within $0.5 \mathrm{~cm}$. Some animals had been skinned, and a correction coefficient was used to calculate their total weight. The coefficient (1.205) was calculated on the basis of 26 animals that I skinned myself.

The young were distinguished from adults (animals at least one year old) by the ossification stage of the epiphyseal cartilage of the radius and ulna or by the annual incremental lines in the tooth cementum (Kauhala and Helle 1990). Young animals are here called juveniles until the end of the year when they were born and subadults in January - May the following year.

The fat deposits around the kidneys and dorsally in the abdominal cavity (inner fat reserves) were removed from 1106 animals and weighed to the nearest $0.1 \mathrm{~g}$. A fat index was calculated by dividing the amount of fat $(\mathrm{g})$ by the body length of the animal $(\mathrm{cm})$. The subcutaneous fat reserves were also removed from 16 animals and weighed to calculate the total fat reserves. An obesity index (Korhonen et al. 1982, Korhonen and Harri 1985), was calculated to describe the amount of fat reserves, and the two indices were compared.

The growth curves of foetuses were calculated from the data for four females raised in a farm. The foetuses were weighed to within $0.1 \mathrm{~g}$, and the crown-rump length was measured to within $1 \mathrm{~mm}$. Both the foetal length and the cube root of foetal weight give a linear growth form when plotted against time (Huggett and Widdas 1951). The foetal growth rate was calculated from these growth

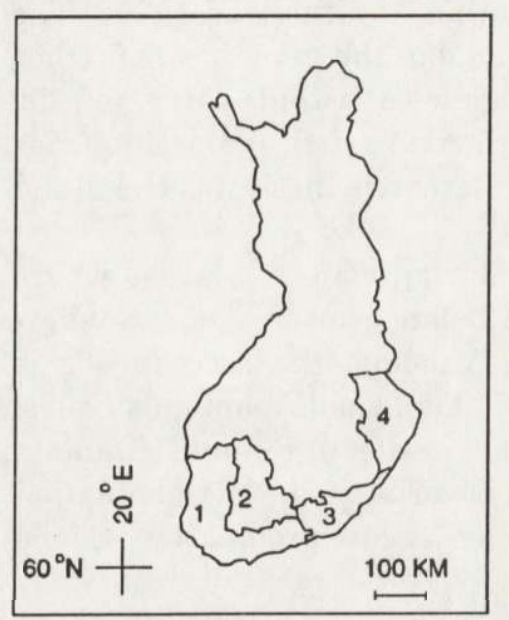

Fig. 1. The study area in Finland. 1 - the provinces of Turku-Pori and Uusimaa, 2 - Häme, 3 - Kymi, and 4 North Karelia. 
lines in two ways: as the relative growth rate (the relative gain of weight or length per day) and by using the formula of Frazer and Huggett (1974).

I used the analysis of variance to compare the mean lengths, weights, and fat indices, unless otherwise noted. The level of statistical significance was 0.05 .

The factors causing variation in the growth and fat reserves of the animals were analyzed by means of regression analysis (Sokal and Rohlf 1981). The study period of $1986-1990$ included climatically very dissimilar years in my study area: 1987, which was extremely cold (mean temperature $1.1^{\circ} \mathrm{C}$ ) 1989 , which was exceptionally warm (mean temperature $5.4^{\circ} \mathrm{C}$ ), and the other years being intermediate.

The independent variables analyzed were: (a) the temperature sum (the sum of the mean daily temperatures above zero) at the end of May, (b) the frost sum (the sum of the mean daily temperatures below zero) from the beginning of October to March 15, (c) the thickness of the snow cover at the end of March, (d) the abundance of small mammals (voles, mice and shrews), (e) the abundance of voles in spring, ( $f$ ) and the abundance of bilberries Vaccinium myrtillus and lingonberries Vaccinium vitis-idaea, the two most common wild berries in Finland.

The climatological data were based on measurements at Evo Game Research Station (H. Koivunen, in litt.) and on annual reports of The Finnish Meteorological Institute (Anon. 1987 - 1991). The number of small mammals was based on snap-trapping at Evo in Häme (720 trap-nights each year; 360 trap-nights from the end of May and 360 from September) to give the best local data on the density of small mammals during the snow-free period. The abundance of bilberries and lingonberries was calculated from game inquiries, as was the abundance of voles in spring (Finnish Game and Fisheries Research Institute). For calculation of the abundance index, see Helle and Kauhala (1987, 1991a).

\section{Results}

\section{Foetal growth}

The foetuses were big enough to be measured and weighed accurately at the age of 32 days, and the growth lines could well be calculated from that point onwards (Fig. 2). The oldest foetuses were 53 days old, the duration of gestation being about 62 days. The relative growth rate was 0.09 (length) or 0.08 (weight). The foetal growth rate, calculated according to the formula of Frazer and Huggett (1974), was 0.14 .

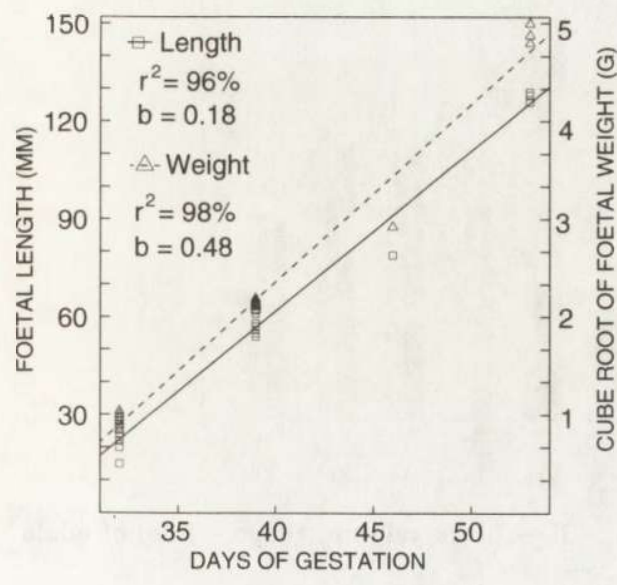

Fig. 2. The growth lines of foetuses of raccoon dog females $(n=4)$ raised in a farm. 


\section{Body length}

There were no statistical differences between the sexes in the mean body length. The mean length of all adult females was $59.9 \mathrm{~cm}(\mathrm{SD}=2.6$, range $=52-69$, $n=363)$, that of all adult males being $60.1 \mathrm{~cm}(\mathrm{SD}=2.8$, range $=54-70.5$, $n=227$ ).

The mean monthly body length of juveniles in Häme and Kymi was particularly small in early autumn of 1987 and large at the same time in 1989 (Fig. 3). The difference between years was still statistically significant in November - December $(p=0.009)$.

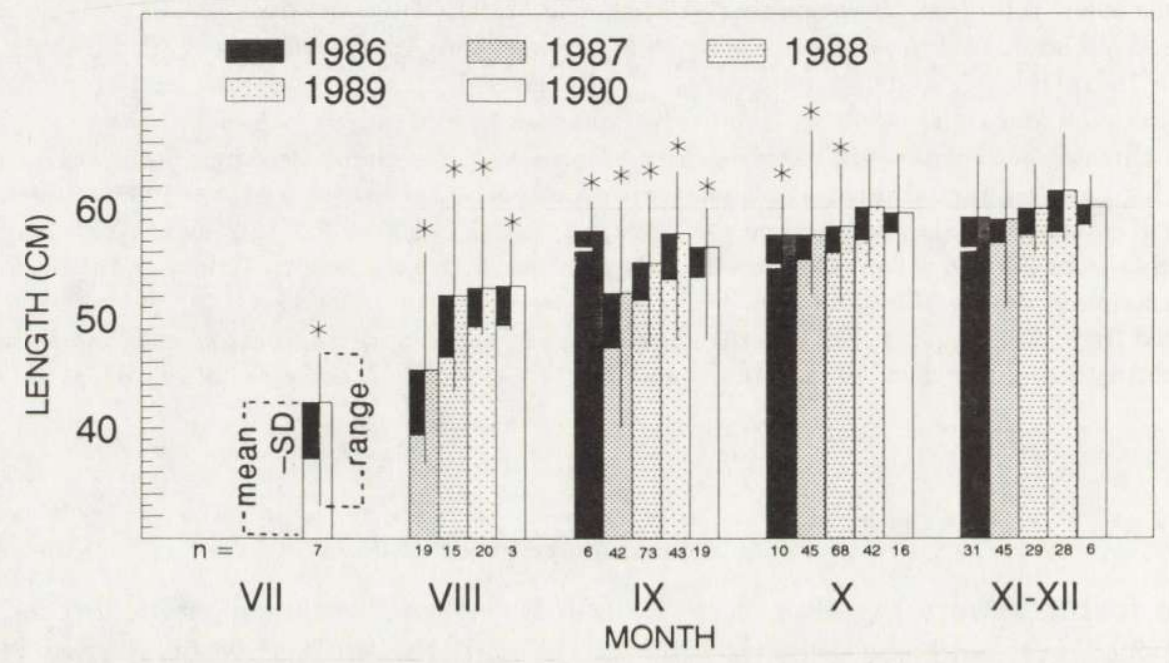

Fig. 3. The body length (mean - large column, -SD - black column, range - line) of raccoon dog juveniles born in the provinces of Häme and Kymi, southern Finland, in 1986 - 1990. The dotted line gives the mean adult body length in Finland. The asterisk shows statistical difference $(p<0.05)$ between juveniles and adults.

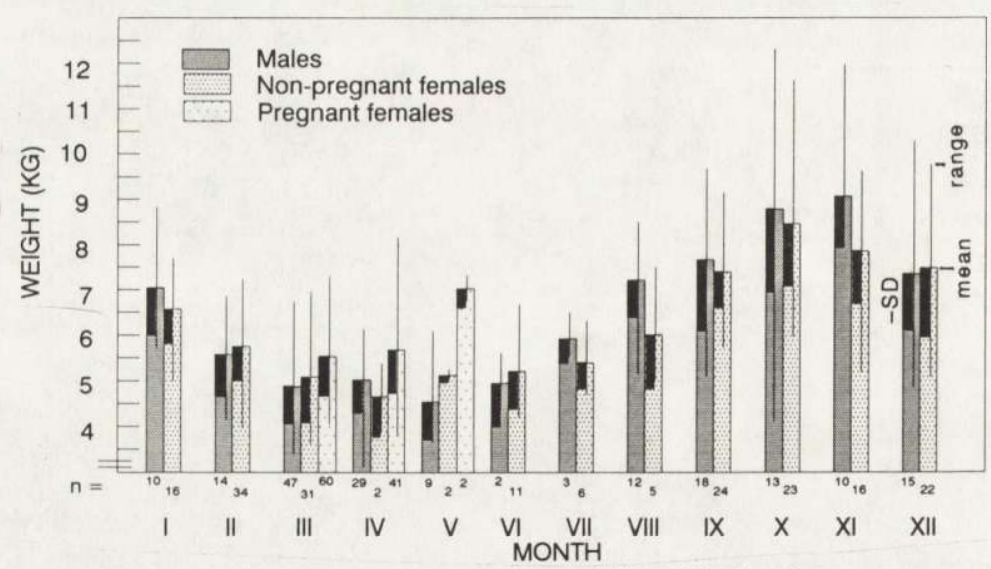

Fig. 4. The monthly body weight (mean - large column, -SD - black column, range - line) of adult raccoon dogs in Finland in $1986-1990$. 
In the southwestern coast, juveniles reached the mean adult body length as early as in September (data only for 1989 , mean $59.7 \mathrm{~cm}, \mathrm{SD}=2.8, n=8$ ), but in Häme and Kymi not before October (in 1989). The mean body length of juveniles in North Karelia in autumn did not differ statistically from that in Häme and Kymi, but the samples were small.

\section{Body weight}

There were no statistical differences between the sexes in the mean monthly body weight of adults (Fig. 4) or juveniles (binomial test). Adults were heaviest in October - November and weighed least in March - June (except pregnant females, pregnancy determined by the existence of corpora lutea). The mean weight of adults in spring was $59 \%$ of that in October - November, the mean difference being $3.5 \mathrm{~kg}$.

No statistical differences in adult weight were found in autumn between the years, but the adult (non-pregnant) females weighed less in March 1987 and 1988 than in March 1990 ( $p=0.006$, Table 1).

Table 1. The weight (pregnant excluded), and fat index of adult raccoon dog females in Finland in March (for period 1987 - 1990).

\begin{tabular}{lcccccc}
\hline Year & \multicolumn{3}{c}{ Weight(g) } & \multicolumn{3}{c}{ Fat index } \\
& $\bar{x}$ & SD & $n$ & $\bar{x}$ & SD & $n$ \\
\hline 1987 & 4719 & 796 & 12 & 1.02 & 0.33 & 20 \\
1988 & 4354 & 462 & 4 & 1.12 & 0.36 & 19 \\
1989 & 5083 & 822 & 5 & 1.49 & 0.48 & 16 \\
1990 & 5814 & 910 & 10 & 1.22 & 0.28 & 31 \\
\hline
\end{tabular}

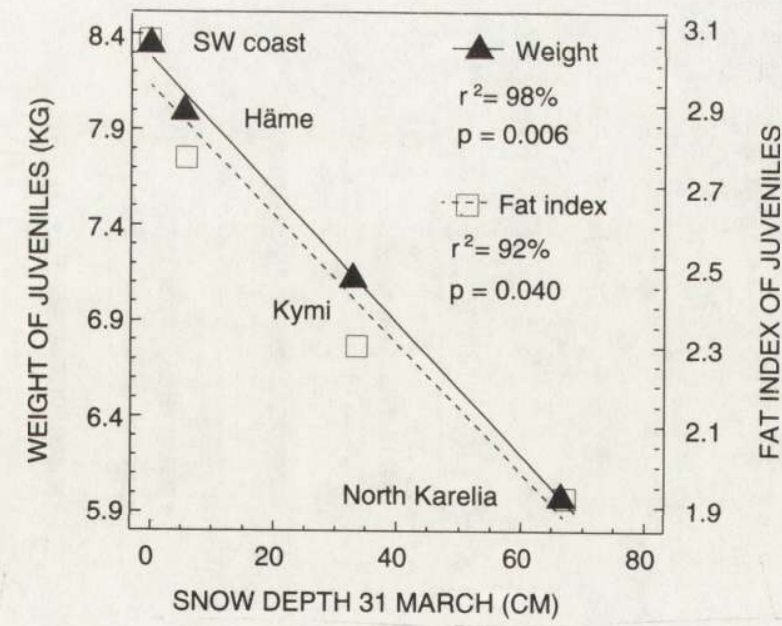

Fig. 5. The regressions between the mean weight and fat index of juvenile raccoon dogs in November - December and snow depth at the end of March 1989 in four provinces of Finland. 
There were some differences between the provinces in the mean body weight of juveniles in late autumn $(p=0.032)$; snow depth at the end of March explained $98 \%$ of the variation (Fig. 5).

In Häme, juveniles were heaviest in autumn 1989 and lightest in autumn 1987 (Figs 6 and 7); temperature sum at the end of May explained $83 \%$ of the variation. The abundance of small mammals explained $77 \%$ of the variation $(p=0.049)$, but partial correlation analysis indicated that temperature sum was more important (temperature sum $r=0.74$, small mammals $r=0.40, n=5$ ). The differences between young born in different years were significant as late as November December in Häme $(p=0.006)$ and March in Kymi $(p=0.002)$.

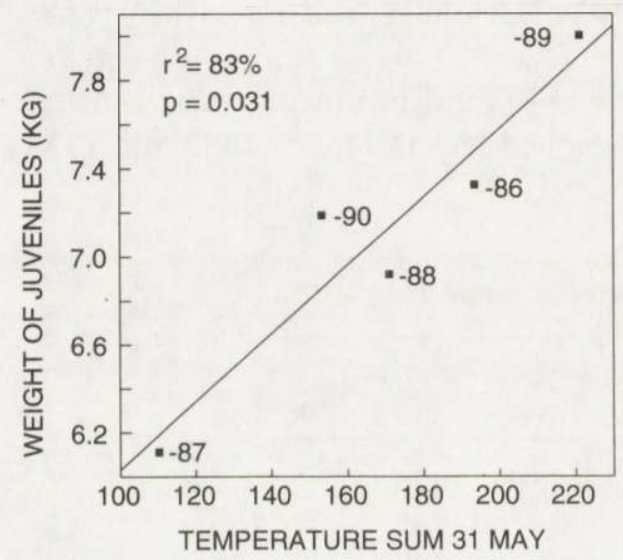

Fig. 6. The regression between the mean weight of juveniles in November - December and the temperature sum at the end of May for period 1986 - 1990 in Häme, southern Finland.

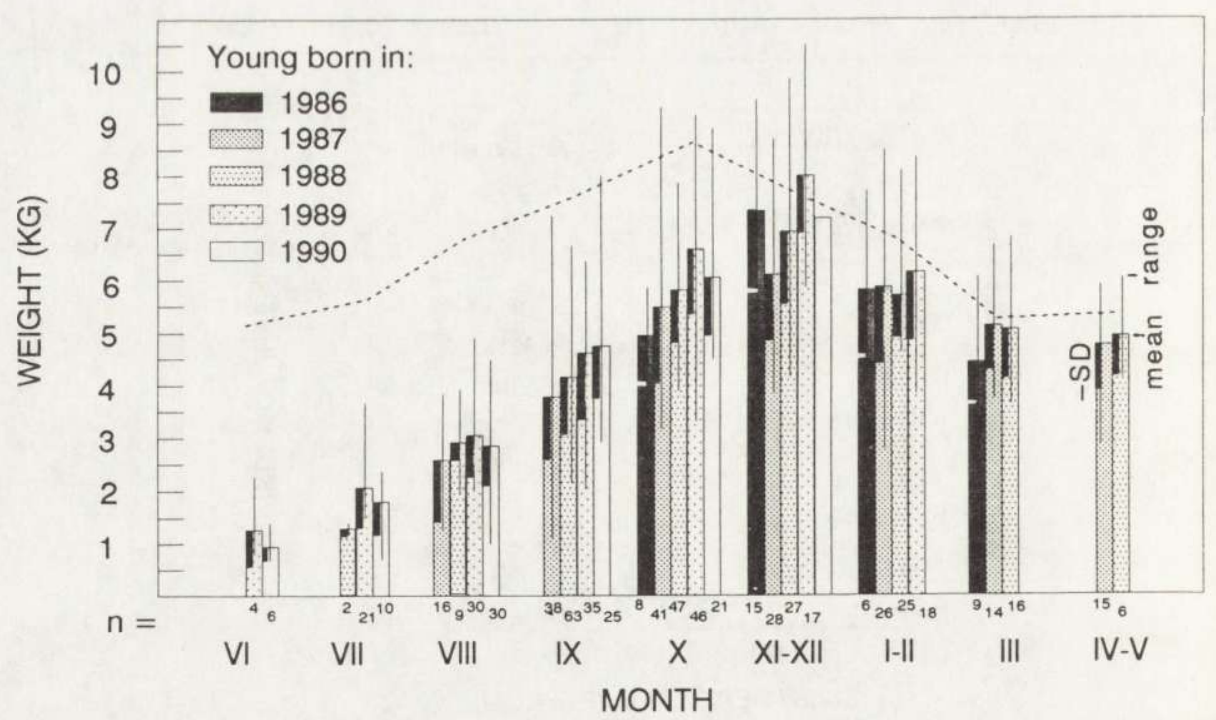

Fig. 7. The body weight (mean - large column, -SD - black column, range - line) of young raccoon dogs born in the province of Häme, southern Finland, in period 1986-1990. The dotted line gives the mean adult body weight. 


\section{Fat reserves}

The amounts of the inner and subcutaneous fats correlated strongly $(r=0.75$, $p=0.0008, n=26$ ) and inner fat of adults averaged $10 \%$ of all fat reserves (subcutaneous + inner). The obesity index correlated strongly with the fat index (all material, $r=0.69, p<0.00001, n=1777$ ). The seasonal variation in the obesity index among adults was parallel to the variation in the fat index, but the magnitude was smaller (Fig. 8). Both indices showed that males are at their fattest as early as October, but females not before November (Figs 8 and 9). The inner fat reserves of adults in May averaged $25 \%$ of those in late autumn.

In March, the fat index of adult females was lowest in 1987 and highest in 1989 ( $p=0.001$, Table 1, Fig. 10); the abundance of voles in the current spring explained $96 \%$ of the variation. The relation between abundance of berries in the previous autumn and the frost sum during the winter also seemed to affect the

Fig. 8. The mean monthly obesity index (according to Korhonen et al. 1982) and the mean monthly fat index of adult raccoon dogs in Finland in period $1986-1990$.
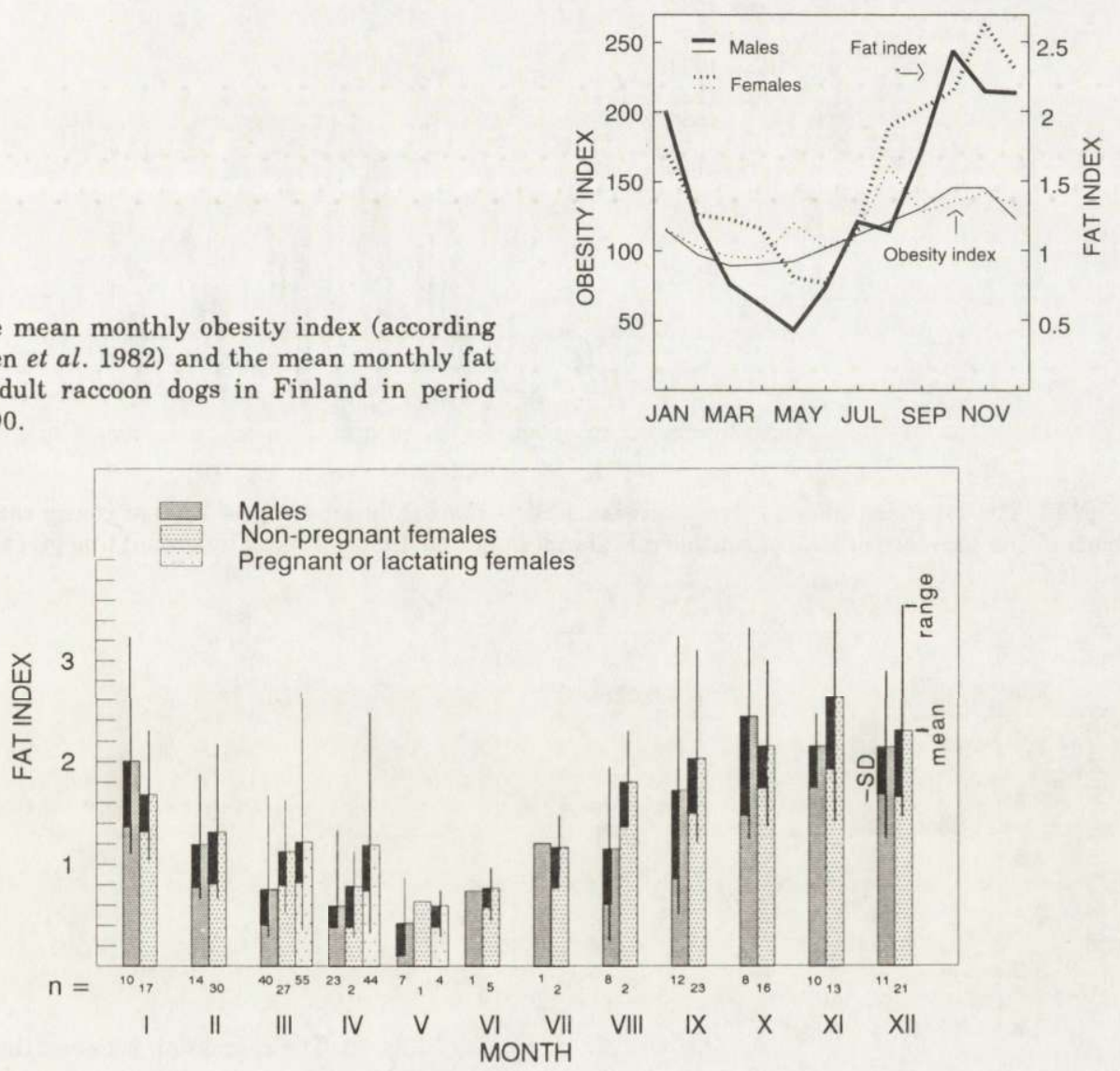

Fig. 9. The monthly fat index (mean - large column, $-\mathrm{SD}$ - black column, range - line) of adult raccoon dogs in Finland in period $1986-1990$. 


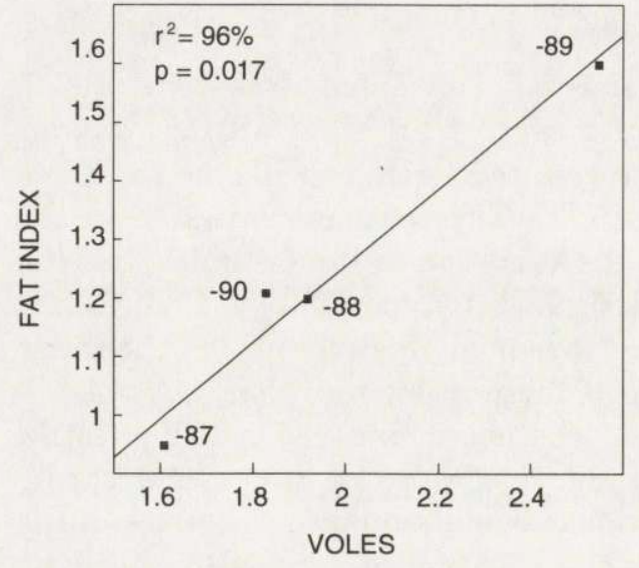

Fig. 10. The regression between the mean fat index of adult females and the abundance of voles in Finland in March in period 1987 - 1990.

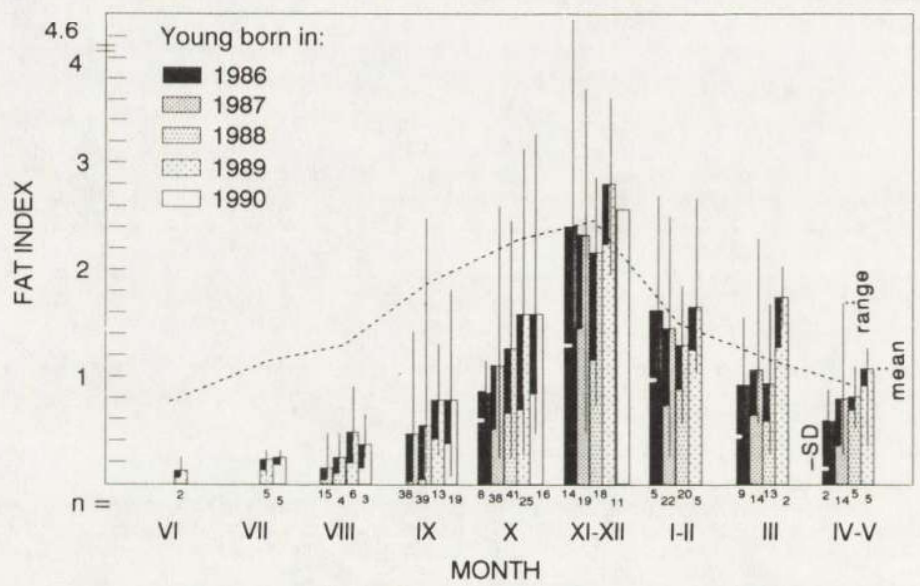

Fig. 11. The fat index (mean - large column, -SD - black column, range - line) of young raccoon dogs born in the province of Häme, southern Finland, in period 1986 - 1990. The dotted line gives the mean adult fat index.

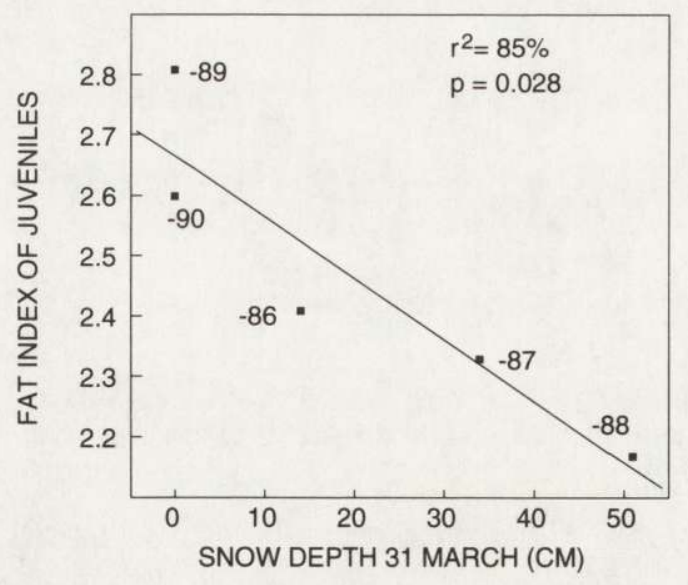

Fig. 12. The regression between the mean fat index of juveniles in autumn and the snow depth at the end of March for period 1986 1990 in Häme, southern Finland. 
fat index of adult females in March $\left(r^{2}=87 \%, p=0.07\right)$. The fat reserves of males in spring were smaller than those of females $(p<0.001)$.

Among juveniles and subadults, no differences in the mean fat indices were found between the sexes except in March, when females had more fat than males $(p<0.05)$. There seemed to be some variation in the mean fat index of juveniles between the provinces in late autumn ( $p=0.093$, Fig. 5), and the difference could still be seen in the breeding season in March ( $p<0.01$ for Häme and Kymi). Snow depth at the end of March explained $92 \%$ of the variation in late autumn.

In Häme, the mean fat index among juveniles in autumn was highest in period $1989-1990$ and lowest in period $1987-1988$ (Fig. 11). Snow depth at the end of March explained $85 \%$ of the variation (Fig. 12).

\section{Discussion}

The foetal growth rate of mammals is low at first, but after a period of differentiation a phase of linear growth with a very high rate follows (Eisenberg 1981). During the latter period, the growth rate of carnivores was between 0.04 and 0.21 , and that of canids varied from 0.08 in the fennec Vulpes zerda to 0.18 in the wolf Canis lupus (Frazer and Huggett 1974). The growth rate of foetuses of raccoon dogs reported by Frazer and Huggett (1974) was 0.10 (the data on the birth weight based on Novikov 1962). The growth rate I calculated with their method was slightly higher (0.14), the difference being due to the difference in birth weight.

The birth weight of raccoon dogs was $60-90 \mathrm{~g}$ in the southeastern Russia (Novikov 1962, Stroganov 1969), and $60-110 \mathrm{~g}$ in the introduced range in the former Soviet Union (Bannikov 1964). The birth weight of the Japanese subspecies $N$. p viverrinus was $105-115 \mathrm{~g}$ in captivity (Ikeda 1983). In the present study, the mean weight of newborn raccoon dogs was $125 \mathrm{~g}$ and even the mean weight of foetuses was $117 \mathrm{~g}$ at the age of 53 days, about ten days before parturition. The experimental animals were raised in a farm, which may have affected foetal growth. However, the maximum weight of a foetus of a wild female I examined was $154 \mathrm{~g}$, the mean weight of foetuses in that litter being $139 \mathrm{~g}(n=7)$. Thus the growth rate and birth weight in Finland seem to be higher than in the other areas, especially in the southeastern Russia.

The lack of sexual dimorphism in size may be due to the monogamous breeding system (Kleiman 1977, Clutton-Brock et al. 1982). The body length of raccoon dogs in the Danube Delta is $54-67 \mathrm{~cm}(\bar{x}=60.6)$ for males and $52-65 \mathrm{~cm}(\bar{x}=59.1)$ for females (Barbu 1972), the maximum values being a little lower than in my study. According to Stroganov (1969), the body length of raccoon dogs in the southeastern Russia is $52-80 \mathrm{~cm}$ for males and $47-60 \mathrm{~cm}$ for females, indicating sexual dimorphism in animals from the mouth of the Ussuri River. The sample size is, however, unknown. Ward and Wurster-Hill (1990) also report sexual dimorphism in the Chinese animals, but they had a sample of only three males and five females, whereas my sample consisted of 227 males and 363 females. 
The weight of adults was rather similar to that in other studies: $4.2-9.2 \mathrm{~kg}$ for males and 3.5 - 8.7 kg for females in the Danube Delta (Barbu 1972), and 4 $-6 \mathrm{~kg}$ in summer and 6-10 kg in winter in the southeastern Russia (Stroganov 1969). However, Bannikov (1964) reported that adults weigh $3-10 \mathrm{~kg}$, usually 3 $-7 \mathrm{~kg}$ in the introduced range; this is a little less than in Finland. As in my study, females in the former Soviet Union reach their maximum fat reserves $1-1.5$ months later than males, and juveniles one month later than females (Bannikov 1964). Juveniles have to invest in growth first and, once they have reached adult length, they can invest in accumulating fat reserves.

Because most raccoon dog cubs are born in May or in the first half of June (Helle and Kauhala 1989), their growth seems to stop at the age of 5-7 months. The length of the snow-free period affects regional variation in the weight and fat reserves of juveniles in autumn, and thus, both the mortality of juveniles during winter and the proportion of reproducing females the following spring (Kauhala 1992).

The weather in spring causes annual variation in the weight and fat reserves, too, and in some areas the annual differences could be seen as late as March (the breeding season). In warm springs the raccoon dogs come into heat earlier than in cold ones (Bannikov 1964), and when cubs are born early, they are older and bigger in late autumn (and sometimes even in the following spring) than those born late. On the other hand, in warm springs the productivity of the environment is higher than in cold ones, which affects the amount of food that is available for lactating females and cubs, which, in turn, may influence the growth rate of juveniles. The regression between the number of small mammals and the weight of juveniles in late autumn also supports this conclusion.

The fat reserves of adult females in spring differed between years, thus indicating that annual differences in the environmental conditions, such as food availability or weather, may affect the fat reserves of adults. The amount of wild berries may affect the amount of fat accumulated in autumn and the weather conditions may affect the amount of fat reabsorbed during winter; so, the relation between these two factors and, especially, the abundance of voles in early spring influence the fat reserves of females in March, when the heat usually takes place.

The fat indices between the sexes differed significantly only in spring, the difference being a consequence of reproduction. Pregnant, and especially lactating, females need fat reserves, which are unnecessary for males and non-reproducing females.

The fat index seems to be a better indicator of fat reserves than the obesity index because the relative change in the fat index was stronger. However, the fat index gives an underestimation of the total amount of fat, as indicated by the comparison between the differences in the mean weight between the seasons (mean difference $3.5 \mathrm{~kg}$ ) and the amount of fat in late autumn $(\max 2.6 \mathrm{~kg}$ ). Thus, there must be other fat reserves in addition to the subcutaneous and inner fat. On the 
other hand, differences in the mean weight between seasons may overestimate the amount of fat because the weights of the fur and the stomach were disregarded.

The ability to accumulate large fat reserves and sleep during the winter is certainly one factor behind the success of the raccoon dog in northern Europe. Especially adult females pass the winter in good condition regardless of the food availability during winter. This contributes to the very high productivity of the raccoon dog in Finland (Kauhala 1992).

Acknowledgements: I thank E. Helle, E. Pankakoski and H. Pöysä for reading the manuscript and providing valuable comments. I am grateful to the hunters who sent me carcasses of raccoon dogs. I also thank $\mathrm{H}$. and R. Koivunen for technical assistance and H. Koivunen for trapping small mammals at Evo Game Research Station and for providing climatological data. The study was supported by the Academy of Finland (Research Council for Agriculture and Forestry) and the Nordic Council for Wildlife Research.

\section{References}

Anonymous 1987-91. Meteorological Yearbook of Finland 86-90: Climatological data 1986-90. The Finnish Meteorological Institute, Helsinki.

Bannikov A. G. 1964. Biologie du chien viverrin en U.S.S.R. Mammalia 28: 1 - 39.

Barbu P. 1972. Beiträge zum Studium des Marderhundes, Nyctereutes procyonoides ussuriensis Matschie, 1907, Aus dem Donaudelta. Säugetierk. Mitt. 20: 375 - 404.

Clutton-Brock T. H., Guinness F. E. and Albon S. D. 1982. Red deer. Behavior and ecology of two sexes. The University of Chicago, Edinburgh University Press, Edinburgh: $1-378$.

Eisenberg J. F. 1981. The mammalian radiations: an analysis of trends in evolution, adaptation, and behavior. The University of Chicago Press, Chicago: $1-610$.

Frazer J. F. D. and Huggett A. St. G. 1974. Species variations in the foetal growth rates of eutherian mammals. J. Zool., Lond. 174: 481 - 509.

Helle E. and Kauhala K. 1987. Distribution history and present status of the raccoon dog in Finland. Suomen Riista 34: 7 - 21. [In Finnish with English summary]

Helle E. and Kauhala K. 1989. Age structure and reproductivity of the raccoon dog population in Finland. Suomen Riista 35: 119 - 127. [In Finnish with English summary]

Helle E. and Kauhala K. 1991a. Distribution history and present status of the raccoon dog in Finland. Holarctic Ecol. 14: 278 - 286.

Helle E. and Kauhala K. 1991b. Reproductivity of the raccoon dog in Finland in 1986-90. Abstracts of 1st European Congress of Mammalogy, 18 - 23 March 1991, Lisboa.

Huggett A. St. G. and Widdas W. F. 1951. The relationship between mammalian foetal weight and conception age. Physiol., Lond. 207: 783 - 788.

Ikeda H. 1983. Development of young and parental care of the raccoon dog Nyctereutes procyonoides viverrinus Temmick, in captivity. Mammal. Soc. Jpn 9: 229 - 236.

Judin V. G. 1977. Enotovidnaja sobaka Primor'ja v Priamur'ja. Nauka, Moskva: 1 - 151.

Kauhala K. 1992. Ecological characteristics of the raccoon dog in Finland. Ph. D. thesis, Helsinki University: 1 - 19 .

Kauhala K. and Helle E. 1990. Age determination of the raccoon dog in Finland. Acta theriol. 35: $321-329$.

Kauhala K., Kaunisto M. and Helle E., in press. Diet of the raccoon dog, Nyctereutes procyonoides, in Finland. Z. Säugetierk.

Kleiman D. G. 1977. Monogamy in mammals. Q. Rev. Biol. 52: 39 - 69.

Korhonen H. and Harri M. 1985. Growth and fur parameter variations of farmed raccoon dogs. Arch. Tierernähr. 35: $761-772$. 
Korhonen H., Harri M. and Asikainen J. 1982. Effect of various diets and energy levels on the growth of farmed raccoon dogs. Savonia 5: $1-9$.

Lavrov N. P. 1971. Itogi introdukcii enotovidnoj sobaki (Npg) v otel'enye oblasti SSSR. Trudy Kafedry Biologii MGZPI 29: $101-160$.

Nasimovic A. A. and Isakov J. A. (eds) 1985. Pesec, lisica, enotovidnaja sobaka: Razmešcenie zapasov, ekologija, ispol'zovanie i ohrana. Nauka, Moskva: $1-160$.

Novikov G. A. 1962. Carnivorous mammals in the fauna of U.S.S.R. Isr. Progr. Sci. Trans., Jerusalem: $1-283$.

Ognev S. I. 1962. Mammals of eastern Europe and northern Asia. Carnivora 2. Isr. Progr. Sci. Trans., Jerusalem: $1-590$.

Sokal R. R. and Rohlf F. J. 1981. Biometry. The principles and practice of statistics in biological research. Second ed. W. H. Freeman and Company, New York: 1-859.

Stroganov S. U. 1969. Carnivorous mammals of Siberia. Isr. Progr. Sci. Trans., Jerusalem: $1-522$.

Ward O. G. and Wurster-Hill D. H. 1990. Nyctereutes procyonoides. Mamm. Species 358: 1-5.

Received 5 October 1992, accepted 8 March 1993. 